Dicle University Journal of Engineering (DUJE)

web: http://dergipark.gov.tr/dumf

Araștırma Makalesi / Research Article

\title{
Otomobil Radyatöründe Su Bazlı Grafen Nanoakışkan Kullanımının Isıl Verimliliğe Etkisinin Deneysel Olarak İncelenmesi
}

\author{
Experimental Investigation of the Effect on Thermal Efficiency by Means of Water- \\ Based Graphene Nanofluid Usage in an Automobile Radiator \\ Tarkan Koca ${ }^{*}$ \\ ${ }^{1}$ İnönü Üniversitesi, Makine Mühendisliği Bölümü, Malatya, tarkan.koca@inonu.edu.tr
}

\begin{tabular}{l} 
MAKALE BİLGİLERİ \\
\hline Makale geçmişi: \\
Geliş: 12 Mayıs 2020 \\
Düzeltme: 1 Temmuz 2020 \\
Kabul: 9 Temmuz 2020 \\
\hline Anahtar kelimeler: \\
Grafen, Nanoakışkan, 1sı transferini \\
geliştirme, araç radyatörü
\end{tabular}

Doi: $10.24012 /$ dumf. 736458

\section{ÖZET}

Bu çalışmada, bir Renault Clio marka otomobil radyatöründe soğutma akışkanı olarak grafen su bazlı nanoakıșkan kullanılmıș ve motor soğutma performansı deneysel olarak incelenmiștir. Deneylerde 1sı transfer hızındaki artıș ve basınç düșüșündeki artıș değerleri irdelenmiștir. Deney düzeneği motor soğutma sistemine benzer şekilde tasarlanmıştır. Dört tip çalışma sıvısı kullanılmıştır. Bunlar saf su ve (0.01-0.02-0.03) grafen nanoparçacık konsantrasyonuna sahip nanoakıskanlardır. Deneyde hacimsel debi 4 ile 16 1/dk arasında 6 farklı debide gerçekleștirilmiștir. Otomobil radyatörüne giris sıcaklığ $10^{\circ} \mathrm{C}$ olarak sabit tutulmuștur. Deneyler laminer akışta gerçekleştirilmiştir. Reynolds sayısı 224 ile 1482 arasındadır. Yapılan deney sonucunda \%0.02 hacimsel nanoparçacık konsantrasyonuna sahip nanokışkan kullanmanın 1sı transfer hızında \%47 artış sağladığı görülmüstür. Toplam 1sı transfer katsayısında \% 52 ve Nusselt sayısında \% 34 maksimum bir artıs elde edilmiştir. Basınç düşüşündeki artış \%49 olarak tespit edilmiştir. Nanopartiküllerin konsantrasyonunu artırarak 1s1l performansların arttığı gözlemlenmiş ancak nanopartiküllerin konsantrasyonunun \%0.02'nin üzerine çıkartıldığında motor soğutma performansının düşmeye başladığı izlenmiștir. Çalışma sonucunda en iyi 1sı transfer değerlerine \%0.02 grafen bazlı su konsantrasyonu kullanıldığında ulaşılmıştır.

\footnotetext{
\begin{tabular}{l} 
ARTICLE INFO \\
\hline Article history:
\end{tabular}

\section{ABSTRACT}

In this study, engine cooling performance of a Renault Clio automobile radiator (heat exchanger) by utilizing graphene water based nanofluids was studied. In the experiments the heat transfer increase were evaluated. In addition, the increase in pressure drop was investigated. Experiment set was designed similar to the engine cooling system. Four types of fluid were employed. These are water and nanofluids with $(0.01-0.02-0.03)$ graphene nanoparticle concentration. In the experiment, the flow rate was adjusted between 4 and $161 / \mathrm{min}$. The coolant inlet temperature to the vehicle radiator is $70{ }^{\circ} \mathrm{C}$. Experiments were carried at the laminar flow. The Reynolds number is between 224 and 1482. Experiments were carried at the laminar flow. The best results were obtained by utilization nanofluid with $0.02 \%$ volumetric concentration of graphene. The enhancement in heat transfer rate was obtained $47 \%$. A maximum enhancement in overall heat transfer coefficient was obtained up to $52 \%$. The maximum increase in the nusselt number was $34 \%$. The pressure drop increased by $49 \%$. As a result, the high thermal efficiency was obtained by using nanofluid.Thermal efficiency was the maximum in the fluid experiment with a volumetric concentration of graphene of $0.02 \%$.
} 


\section{Giriş}

Günümüzde 1sı transferini iyileştirmeye yönelik çok sayıda çalıșma yapılmaktadır. Isı transferini artırmak için genişletilmiş yüzeyler, doğal akış ve cebri akış gibi çeşitli metotlar kullanılmaktadır. Son zamanlarda bu yöntemlere ek olarak nanoakışkanlar kullanılmaya başlanmıştır. İlk olarak Maxwell, 1881 yılında akışkanlara katı parçacıklar ekleyerek 1sı transferini artırmaya çalışmıştır [1]. Bu katı parçacıklar 10 ile 100 arasında nanometre boyutuna sahiptir ve nanoakışkanlar bu nanoparçacıklar içerirler [2]. Isıl verimi yükseltmek ve kullanılan akışkanın 1sı transferi performansını artırmak amacıyla akışkanlara nanoparçacıklar eklenmektedir. Nanoakışkanlar daha önce kullanılan akışkanlara oranla oldukça yüksek 1sıl iletkenlik değerlerine sahiptirler [3]. Nanoakışkanları mühendislik uygulamalarında kullanabilmek için termofiziksel özelliklerin yanı sıra 1s1 transfer özelliklerinin de araştırılması gerekmektedir [4].

Soğutma sistemlerinde de 1s1 transferi oldukça önemlidir. Is1 transferinin artırılması soğutma sistemlerinin de verimini artıracaktır. Soğutma performansının arttırılması da endüstride ihtiyaç duyulan bir eksikliği gidermiş olacaktır. Otomotiv motorlarında soğutma sistemleri oldukça önemlidir. Soğutma sisteminde kullanılan sıvının ısıl performansının yüksekliği araç motorunun verimini artıracaktır. Bir 1s1 eşanjörü tipi olan radyatörler araçlarda soğutma sisteminin önemli parçalarından biridir. Radyatörün görevi, motordan 1sınmış olarak gelen sıviyı soğutarak, bu sıvı sayesinde motorun soğutulmasını sağlamaktır. Motordan ısınmış olarak gelen su radyatörde soğutularak tekrar motora gönderilmektedir. Radyatöre gelen sıvının soğutulması fanlar yardımıyla hava üflenerek gerçekleşmektedir. Radyatörler kanatçıklı yapıda olduklarından 1 sı transfer yüzeyleri oldukça fazladır. İçten yanmalı motorlarda önemli prensiplerden biri motor sıcaklığının belirli değerler aralığında tutulmasıdır. Araç motorunun fazla 1sınması malzemelerin mukavemet ve termal özelliklerini bozmakta ve yakıt tüketimini de artırmaktadır [5]. Soğutma sisteminin en önemli özelliklerinden biri motor çalışma sıcaklığını belirli aralıklarda tutmasıdır. Motorlarda soğutma sıvısı olarak farklı tip akışkanlar kullanılarak 1S1 transfer miktarı ve 1S1 transfer hızı artırılmaya çalışılmıştır [6]. Bu nedenle otomobil radyatöründe nanoakışkan kullanılarak, mekanik kayıpların azaltılması ve motorun 1sıl verimliliğini artırılması amaçlanmıştır [7,8]. Leong vd. [9] bir otomobil radyatöründe Bakır $(\mathrm{Cu})$ etilen glikol nanoakışkan kullanmış ve pompa gücünün $\% 12.13$ 'e kadar arttığını gözlemlemişlerdir. Peyghambarzadeh vd. [10] su bazlı alüminyum oksit $\left(\mathrm{Al}_{2} \mathrm{O}_{3}\right)$ kullanarak otomobil radyatör soğutma performansını artırmış olup termal verimliliğin \% 45 arttığını hesaplamışlardır. Peyghambarzadeh vd. [11] bir araç radyatörü aracılığıla su bazlı bakır oksit $(\mathrm{CuO})$ ve demir oksit $\left(\mathrm{Fe}_{2} \mathrm{O}_{3}\right)$ nanoakışkan kullanarak 1s1 transferini deneysel olarak incelemiş ve toplam 1S1 transfer katsayısında \%9 artış tespit etmişlerdir. Naraki vd. [12] bir araç radyatörüne su bazlı bakır oksit $(\mathrm{CuO})$ nanoakışkan koyarak deneysel olarak incelemiş ve araç radyatörü için toplam 1S1 transfer katsayısının \%8'e kadar $\operatorname{arttığı~sonucuna~varmışlardır.~Hussein~ve~vd.~}$ [13] bir araç radyatöründe su bazlı silikon dioksit $\left(\mathrm{SiO}_{2}\right)$ nanoakışkan kullanarak 1sı transfer oranının \%50 arttığını belirlemişlerdir. Nieh vd. [14] bir araç radyatöründe alüminyum oksit $\left(\mathrm{Al}_{2} \mathrm{O}_{3}\right)$ ve titanyum dioksit $\left(\mathrm{TiO}_{2}\right)$ nanoakışkan kullanarak 1sıl performansı artırmışlardır. Baby ve Ramaprabhu [15] \%0.05 konsantrasyon grafen-su nanoakışkanın ile yaptıklar1 deneyde isıl transferinde $25{ }^{\circ} \mathrm{C}$ 'de $\% 16$ ve $50{ }^{\circ} \mathrm{C}$ sicaklıkta ise \%75 artış elde etmişlerdir. Chavan ve Pise [16] bir otomobil radyatörüne su bazlı alüminyum oksit $\left(\mathrm{Al}_{2} \mathrm{O}_{3}\right)$ uygulayarak 1s1 transfer verimliliğini $\% 45$ 'e çıkarmışlardır. Heris vd. [17] bir araç radyatöründe su bazlı bakır oksit $(\mathrm{CuO})$ nanoakışkanı kullanmış ve radyatörün isıl verimliliğini \%55'e çıkartmışlardır. AkhavanZanjani vd. [18] \%0.02'lik konsantrasyonlu grafen-su nanoakışkanı kullandıkları deneyde 1sıl iletkenlik katsayısında \%10.3 ve 1sı taşınım katsayısında \%14.2 artış tespit etmişlerdir. Kılınç vd. [19] araç radyatörüne ait soğutma performansinı saf su, grafen oksit (GO)-saf su ve grafen nano ribon (GNR)-saf su nanoakışkanları kullanarak incelemişler ve $U$ 
değerlerindeki en yüksek ortalama artış oranlarının \%0.01 GO-saf su, \%0.02 GO-saf su ve \%0.01 GNR-saf su nanoakışkanları için sirasiyla \%6.9, \%32 ve \%18.9 olduğu görülmüştür. Tüm sıcaklıklar için toplam 1s1 transferi katsayısındaki ortalama artış, saf suyla kıyasla \%0.01 GO için \%5.41, \%0.02 GO için $\% 26.08$ ve $\% 0.01$ GNR için \%15.62 olarak hesaplanmıştır. Kılınç vd. [20] taşıt radyatörünün soğutma performansını, saf su, grafen oksit (GO) ve grafen nano ribon (GNR) nano sivıları kullanarak deneysel olarak araştırmışlar ve toplam 1sı transfer katsayısı tüm sicaklıklar için, hacimce \% 0.01 nanoakışkan için \% 5.41 ve hacimce \% 0.02 nanoakışkan için $\% 26.08$ geliştirmişlerdir. Kılınç vd. [21] grafen nanoribbonun soğutma sıvısı olarak kullanıldığı bir otomobil radyatöründe 1s1 transfer performansını deneysel olarak incelemişler ve 1s1 transfer katsayılarında iyileşmeler kaydetmişlerdir. Kılınç vd. [22] araç radyatöründeki 1s1 transferi performans artışını saf su, su tabanlı grafen oksit ve su tabanlı grafen nano ribon nanoakışkanları kullanılarak deneysel olarak incelemişler ve 1s1 transferi performansında gelişmeler sağlamışlardır.

$\mathrm{Bu}$ çalışmada araç soğutma sisteminde soğutma sıvısı olarak su bazlı grafen kullanılmıştır. Grafen, bir atom kalınlığında, karbon atomlarının tek düzlemde altıgen yapıda dizilmesiyle oluşan iki boyutlu yapıdadır [23] . Grafen, mekanik, 1sıl ve elektriksel özellikler bakımından üstündür [24]. Grafen parçacıkları içeren nanoakışkanlar, araştırmalarda önem kazanmaktadır. Grafitin ısı iletim katsayısı çok yüksektir. Grafit konsantrasyonunun artırıldığg 1 nanoakışkanlarda çökelme olmaktadır. Grafen oksit'in 1sıl iletkenliği grafitten daha düşüktür. Fakat grafen oksit kullanıldığı nanoakışkanda kararlılık artmakta ve çökelme olmamaktadır [25]. Literatürde bulunan çalışmaların hepsinde araç radyatöründe nanoakışkan kullanımının ısıl verimliliği artırdığı görülmektedir.

$\mathrm{Bu}$ çalışmada $1200 \mathrm{cc}$ bir motora ait soğutma sistemi esas alınmış olup deney düzeneği araç soğutma sistemine benzer olarak tasarlanmıştır. Saf su ve üç tip hacimsel grafen nanoparçacık konsantrasyonu soğutucu akışkan olarak kullanılmıştır. Is1 transfer hızı, toplam 1s1 transfer katsay1s1 ve Nusselt sayıs1 gibi 1sıl performans parametreleri ile basınç düşümü deneysel olarak incelenmiştir. Deneylerde hacimsel debi 4-16 lt/dk aralığında olup araç radyatörüne akışkan giriş sıcaklığ $170{ }^{\circ} \mathrm{C}$ olarak sabit tutulmuştur. Reynolds sayıs 224 ile 1482 aralığında olup akış laminer olarak gerçekleşmiştir.

\section{Deneysel Çalışma}

$\mathrm{Bu}$ çalışmada dört farklı tip soğutucu akışkan kullanılmıştır. Öncelikle saf su kullanılmış olup diğerleri ise \%0.01, \%0.02, \%0.03 konsantrasyonlara sahip su bazlı grafen nanoakışkanlardır. Konsantrasyon değerleri hacimsel olarak hesaplanmış ve karışımlar bu şekilde hazırlanmıştır. Nanoakışkanlar Ortadoğu Teknik Üniversitesi Teknoparkında hazırlanmış ve tedarik edilmiştir. Grafen nanopartiküllerinin termo-fiziksel özellikleri Tablo 1'de verilmektedir.

Tablo 1. Grafen nano partiküllerinin termofiziksel özellikleri [26]

\begin{tabular}{ll}
\hline Fiziksel Özellikler & Değerler \\
\hline Parametre Değer Saflığ1 & $\% 99.9$ \\
Parçacık yaklaşık boyutu $(\mathrm{nm})$ & 3 \\
Spesifik yüzey alanı $\left(\mathrm{m}^{2} / \mathrm{g}\right)$ & 2630 \\
Yığın yoğunluğu $\left(\mathrm{g} / \mathrm{cm}^{3}\right)$ & 0.3 \\
Gerçek yoğunluk $\left(\mathrm{g} / \mathrm{cm}^{3}\right)$ & 2 \\
Isı iletkenliği (W/mK) & 5000 \\
Özgül ısı $\quad(\mathrm{J} / \mathrm{kgK})$ & 502.7 \\
\hline
\end{tabular}

Deneyde kullanılan $70{ }^{\circ} \mathrm{C}$ deki saf suyun yoğunluğu $0.9777 \mathrm{~g} / \mathrm{cm}^{3}, \mathrm{c}_{\mathrm{p}}$ değeri $4189 \mathrm{~J} / \mathrm{kgK}$, 1s1l iletkenlik katsayıs1 $0.6631 \mathrm{~W} / \mathrm{mK}^{\prime}$ dir. Hacimce \%0.02 nanoakışkanın ise yoğunluğu $0.997 \mathrm{~g} / \mathrm{cm}^{3}, \mathrm{c}_{\mathrm{p}}$ değeri $4189 \mathrm{~J} / \mathrm{kgK}$, 1s1 iletkenlik katsayıs $0.7732 \mathrm{~W} / \mathrm{mK}$ 'dir.

\section{Deney düzeneği}

Bu deneysel çalışmada Renault Symbol 1200cc motor radyatörü kullanılmıștır. Radyatör içindeki akışkanı soğutmak için çalışma hızı 900-1000 dev/dak olan DC motorlu bir fan kullanılmıştır. Radyatör ölçüleri Tablo 2'de verilmiştir. 
Tablo 2. Radyatör Ölçüler

\begin{tabular}{ll}
\hline Büyüklükler & Değerler \\
\hline Uzunluk $\times$ En $\times$ Yükseklik $(\mathrm{mm})$ & $350 \times 23 \times 378$ \\
Ana boru çapı $(\mathrm{mm})$ & 32 \\
İç tüp boru çapı $(\mathrm{mm})$ & 2.3 \\
Boru uzunluğu $(\mathrm{mm})$ & 300 \\
Boru kesit alanı $\left(\mathrm{mm}^{2}\right)$ & 66.474 \\
Borunun hidrolik çapı $(\mathrm{mm})$ & 4.333 \\
Boru çevresi $(\mathrm{mm})$ & 61.095 \\
Tüpün yüzey alanı $\left(\mathrm{mm}^{2}\right)$ & 18232.97 \\
\hline
\end{tabular}

Deney düzeneğinin şematik akış diyagramı şekil 1 'de gösterilmektedir.

Şekil 1. Deney seti ve akış diyagramı

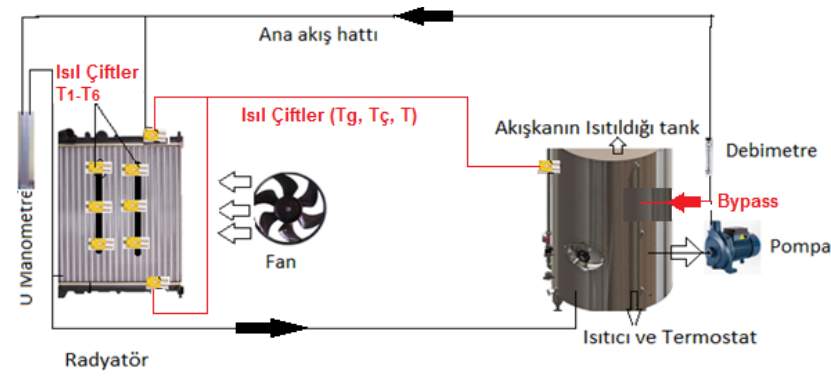

Deney setinde Renault clio symbol 1200 cc motor radyatörü, santrifüj pompa (tek kademeli), depolama tankı, gövde termostatlı elektrikli su 1sitıcısı, elektrikli soğutma fanı (DC), güç kaynağı (AC), debi ölçer, bir manometre (U tüp), dijital gösterge sicaklık kontrolörüne sahip 9 adet K 1 sıl çift ve kontrol ünitesi kullanılmıştır. Araç üzerindeki ile aynı tip orijinal mais marka pompa kullanılmıştır. Giriş akış hattı depolama tankına, çıkış akış hattı bypass hattına ve otomobil radyatörüne bağlıdır. Depodaki suyu 1sıtmak için $2000 \mathrm{~W}$ güç girişine sahip bir elektrikli su 1sıtıcısı kullanılmıştır. Pompa giriş çıkışına by-pass olacak şekilde iki adet sürgülü valf kullanılmıştır. By-pass sisteminin amacı debiyi ayarlayabilmektir. Deney setinde \%4 hassasiyete sahip 2-18 lt/dk aralığında ölçüm yapabilen bir debimetre kullanılmıştır.

Basınç farkını ölçmek için U tipi manometre kullanılmıştır. Manometrenin ölçüm aralığı 0200 mmHg'dir. Manometrenin girişi araç radyatörüne, çıkışı 1sıtma yapılan depoya bağlanmıştır. Deney setinden alınan bilgilerin gösterimini ve bilgisayara aktarımını sağlayan tarayıcı 16 girişe sahiptir. Isıl çiftler ile sıcaklık ölçümü yapılmıştır. $0.2^{\circ} \mathrm{C}$ hassasiyete sahip K 1sıl çiftler kullanılmıştır. Isıl çiftlerin biri radyatör girişine, diğeri radyatör çıkışına yerleştirilmiştir. Üçüncü 1sıl çift soğutma sıvısının sicaklığını ölçmek için 1sıtma deposuna, diğer altı 1sıl çift ise otomobil radyatörünün dış yan yüzeyinin farklı noktalarına yerleştirilmiştir. Bu altı 1sıl çiftin amacı radyatörün ortalama yüzey sıcaklığını ölçmektir. Deney seti bir AC kaynağ 1 ile beslenmektedir. Sistemi kontrol etmek için aurdino kart üzerine program yazılmıştır. Kontrol sistemi, güç kaynağını, santrifüj pompay1, radyatör fanını ve elektrikli 1sıtıcıyı kontrol etmektedir. Bu kontrol sistemi radyatöre akışkanın istenilen debilerde ve $70{ }^{\circ} \mathrm{C}$ sabit sıcaklıkta girmesini sağlamaktadır.

Deneye başlamadan sıvı tankı çalışma sıvısı ile doldurulmuş ve elektrikli isıtıcı ile isıtılmıştır. Yani bir nevi içten yanmalı motorun 1sıtma görevini yapmaktadır. Termostat ile sicaklık sabit tutulmaya çalışılmıştır. Pompa devreye sokularak akış başlamıştır, vanalar yardımıyla sabit debiler ayarlanmıştır. Radyatöre ulaşan sıcak akışkan elektrikli fan yardımıyla soğutulmuştur. $\mathrm{Bu}$ arada isıl çiftler ile belirlenen noktalardaki sicaklıklar ölçülmüştür. Manometre yardımıyla basınç düşüş değeri okunmuştur. Deney sonucunda elde edilen verilere göre 1S1 transfer miktar1, toplam 1S1 transfer katsayıs1, Nusselt sayıs1, Reynolds sayıs1 ve araç radyatörü boyunca deney sıvısının basınç düşüşü hesaplanmıştır. Tüm deneyler, saf su ve $\% 0.01, \% 0.02, \% 0.03$ su bazlı grafen konsantrasyonunda yapılmış ve bu deneyler 4,6 , $8,10,12,16$ lt/dk olmak üzere 6 farkl1 debide gerçekleşmiştir. Radyatöre giriş sıcaklığ $70{ }^{\circ} \mathrm{C}$ olarak ayarlanmıştır. Saf su ve \%0.01, \%0.02, 0.03 hacimsel grafen konsantrasyonda yapilan deneylerde ortalama 4 dakikalık sürede kararlı durum oluşup değerler okunmuştur. Deney setinde bulunan malzemelerin özellikleri tablo 3 'de verilmiştir. 
Tablo 3. Deney setinde bulunan malzemeler

\begin{tabular}{ll}
\hline $\begin{array}{l}\text { Kullanılan } \\
\text { Cihazlar }\end{array}$ & Özellikleri \\
\hline $\begin{array}{l}\text { Araç Radyatörü } \\
\text { Güç Kaynağı }\end{array}$ & $1200 \mathrm{cc}$ motor radyatörü \\
Akış Ölçer & Hassasiyet $\% 4$ \\
Manometre & Civalı U manometre \\
Is1l Çiftler & Sicaklik Aralığı: $0 \sim 800{ }^{\circ} \mathrm{C}$, \\
& K-tipi, Hassasiyet $0.2{ }^{\circ} \mathrm{C}$ \\
Su Isıtıcı & 2000W \\
Termostat & Gövde tipi Hassasiyet $1{ }^{\circ} \mathrm{C}$ \\
Pompa & Tek kademeli santrifüj pompa \\
Su Tank1 & 25 litre kapasiteli depo \\
Valfler & \\
Kontrol Paneli & \\
\hline
\end{tabular}

\section{Yapılan Hesaplamalar}

Bu çalışmada, aşağıdaki denklemler yardımıyla, farklı sicaklık ve hacimsel konsantrasyonlara bağlı olarak nanoakışkanın yoğunluğu, özgül 1S1s1, viskozitesi ve 1s1 iletim katsay1s1 hesaplanmıştır [27-33].

$\rho_{n a}=\emptyset \rho_{p}+(1-\emptyset) \rho_{s}$

$(\rho C p)_{n a}=\emptyset(\rho C p)_{p}+(1-\emptyset) \rho_{s}$

$\mu_{n a}=\left(1+7.3 \emptyset+123 \emptyset^{2}\right) \mu_{s}$

$k_{n a}=\frac{k_{p}+2 k_{s}+2\left(k_{p}-k_{s}\right) \emptyset}{k_{p}+2 k_{s}-2\left(k p_{p}-k_{s}\right) \emptyset} k_{s c}$

Denklemlerde nanoakışkanın $\rho_{\text {na }}$ yoğunluğunu $\mathrm{Cp}_{\text {na }}$ özgül 1sısını $\mu_{\text {na }}$ viskozitesini ve $\mathrm{k}_{\mathrm{na}}, 1 \mathrm{~s} 1$ iletkenliğini belirtir. $\rho_{\mathrm{p}}, \mathrm{Cpp}$ ve $\mathrm{kp}$, nanoparçacıkların yoğunluğu, özgül 1s1 ve 1S1 iletkenlik katsayısıdır. $\rho s, \mathrm{Cps}, \mu$ s ve ks suyun yoğunluğu, özgül 1S1S1, viskozitesi ve 1S1 iletkenlik katsayısıdır.

Aşağıdaki denklem yardımıyla ısı transfer hızı bulunabilir. Burada Q, 1sı transfer miktarı, Cp sıvının özgül 1sısı, Tg ve Tç otomobil radyatörünün sıvı giriş ve çıkış sıcaklığıdır.

$Q=\dot{\mathrm{m}} C p(T g-T c ̧)$

Aşağıdaki denklemler ile radyatöre sıvı giriş ve çıkış sıcaklığının ortalaması ile araç radyatörünün ortalama yüzey sicaklığı bulunabilir.

$$
\begin{aligned}
& \text { Tort }=(T g-T \zeta) / 2 \\
& \text { Ty }=\frac{\mathrm{T} 1+\mathrm{T} 2+\cdots+\mathrm{T} 6}{6}
\end{aligned}
$$

Burada Tg sıvı giriş sıcaklığı ve Tç da S1vı çıkış sıcaklığıdır. Ty araç radyatörünün ortalama yüzey sıcaklığıdır. $T_{1}, T_{2}, T_{3}, T_{4}, T_{5}$ ve $T_{6}$, radyatörün farklı noktadaki yüzey sıcaklıklarıdır.

Is1 transfer katsayısını ve toplam 1s1 transfer katsayısı bulmak için aşağıdaki denklemler kullanılır.

$$
\begin{aligned}
& H=\frac{\mathrm{Q}}{\text { n.As. }(\mathrm{Tg}-\mathrm{T} \zeta)} \\
& U=\frac{\mathrm{Q}}{\text { n.As.OrtLogT }}
\end{aligned}
$$

Burada H 1s1 transfer katsay1s1, Q 1S1 transfer hızı, $\mathrm{n}$ radyatör borusu sayısı, As yüzey alanı, U toplam 1sı transfer katsayıs1, As Radyatör yüzey alanı ve OrtlogT logaritmik ortalama sicaklık farkıdır.

Ortlog $T=\frac{T g-T c}{\ln T g / T c}$

Basınç düşüş değeri aşağıdaki denklem ile hesaplanabilir.

$\triangle P=\left(\rho_{H g}-\rho\right) g \Delta h$

$\Delta \mathrm{P}$ basınç düşüş değerini, $\rho_{\mathrm{Hg}}$ civa yoğunluğunu; g yerçekimi ivmesini; $\rho$ sıvının yoğunluğunu, $\Delta \mathrm{h}$ ise manometredeki civa yüksekliğini gösterir.

Reynolds sayıs1, Nusselt say1s1 ve Prandtl say1s1 aşağıdaki denklemler kullanılarak hesaplanabilir.

$R e=\rho v d_{H} / \mu$

$N u=h d / k$

$\operatorname{Pr}=\mu C p / k$

Re, Reynolds sayısını, $\rho$ sıvı yoğunluğunu; $v$ sıv1 akış hızını; $\mathrm{d}_{\mathrm{H}}$ radyatör borusunun hidrolik çapını $\mu$ sıvı viskozitesini, $\mathrm{Nu}$, Nusselt sayısını, h 1sı transfer katsayısın1, $d_{H}$ radyatör borusunun hidrolik çapını ve k 1sı iletkenlik katsayısını, Pr Prandtl sayısını, Cp özgül ısıyı belirtir.

Radyatör borularının kesit alanı, yüzey alanı, hidrolik çapı ve çevresi aşağıdaki denklemler ile hesaplanmaktadir.

$$
\begin{aligned}
& A c=\frac{\pi d^{2}}{4}+(D-d) d \\
& A s=\text { C. } l \\
& d_{H}=4 A c / C \\
& C ̧=\pi d+2(D-d)
\end{aligned}
$$

Ac radyatör borusu kesit alanını, D radyatör borusunun ana çapını, $d$ radyatör tüp çapını, As 
radyatör borusu yüzey alanını, Ç radyatör borusunun çevresini, $\mathrm{L}$ radyatör borusunun uzunluğunu, $\mathrm{d}_{\mathrm{H}}$ radyatör borusunun hidrolik çapını gösterir.

\section{Belirsizlik Analizi}

Belirsizlikler akışkan debisi, radyatör boyutları ve radyatör giriş ve çıkış sıvısı sıcaklığı, radyatör yüzey sıcaklıkları ve diğer sıcaklıkların ölçüm hataları nedeniyle oluşmaktadır. Toplam 1s1 transfer katsayısındaki hata radyatör yüzey sıcaklıkları dışındaki tüm ölçüm hatalarından kaynaklanırken, 1 S1 transfer oranındaki belirsizlik, akışkan debisi ve radyatör giriş ve çıkış sıvı sıcaklığı ölçüm hatalarından kaynaklanmaktadır. Basınç düşmesindeki belirsizlik manometre sıvısı (cıva) yüksekliğinin ölçüm hatasından ortaya çıkmaktadır. Reynolds sayısındaki belirsizlik, akışkanın hacimsel debisinin ve radyatör borularının çapının ölçüm hatalarına bağlı olarak ortaya çıkmaktadır. Hidrolik çaptaki belirsizlik ise radyatör boru çaplarının ölçüm hataları nedeniyle ortaya çıkmaktadır. Bu deneysel çalışmada, istenen tüm parametrelerdeki belirsizlikler Holman [28] tarafindan önerilen teknik kullanılarak hesaplanmış ve tüm bu belirsizlikler Tablo 4'te verilmiştir.

\section{Tablo 4. Paramatrelerin belirsizlik analizi}

\begin{tabular}{lll}
\hline Parametreler & $\begin{array}{l}\text { Ölçüm } \\
\text { Aralıkları }\end{array}$ & Belirsizlikler \% \\
\hline $\mathrm{Nu}$ & $4.92-9.89$ & 5.04 \\
$\mathrm{U}$ & $76-193$ & 3.78 \\
$\mathrm{Q}$ & $2628-6948$ & 4.3 \\
$\mathrm{Re}$ & $224-1643$ & 4.08 \\
$\mathrm{D}_{\mathrm{H}}$ & 4.333 & 0.39 \\
\hline
\end{tabular}

\section{Sonuçlar ve Tartışmalar}

Deney düzeneğinin güvenilirliği ve doğruluğu, 1S1 transfer oran1, toplam 1s1 transfer katsay1s1, Nusselt sayısı, basınç düşümü gibi istenen nanoakışkan parametreleri hesaplanmadan önce incelenmiştir.

Nusselt sayısının deneysel sonuçları, laminar akış için Shah-London [29] korelasyonlarından elde edilen değerlerle karşılaştırılmıştır.

$$
\begin{aligned}
& \left(\operatorname{RePr} \frac{d_{H}}{L}\right) \geq 33.33 \text { için } \\
& N_{u}=\left(1.953 \operatorname{RePr} \frac{d_{H}}{L}\right)^{1 / 3}
\end{aligned}
$$

$$
\begin{aligned}
& \left(\operatorname{RePr} \frac{d_{H}}{L}\right) \leq 33.33 \text { için } \\
& N_{u}=4.364+0.0722\left(1.953 \operatorname{RePr} \frac{d_{H}}{L}\right)
\end{aligned}
$$

Saf su için Nusselt sayısının deneysel sonuçları, \%3.78'lik ortalama bir hataya sahip ShahLondon denklemleri ile uyumludur.

\section{Su Bazlı Grafen Nanoakışkanların Isı Transfer Performansı}

Saf su ile yapılan deney sonuçları referans değerleri kabul edilmiş ve nanoakıșkanlar ile yapılan deneylerden elde edilen sonuçlar bu değerlerle kıyaslanmıștır. Isı transferi miktarı, toplam 1s1 transferi katsay1s1, Nusselt sayıs1 ve basınç düşüşündeki miktar tüm deneyler için hesaplanmıştır. Elde edilen sonuçlar yapılan diğer çalışmalarla uyumludur. Örneğin Kılınç ve arkadaşlarının [19] yaptıkları araç radyatörü soğutma çalışmasında da GO-saf su ile yapılan deneylerde en iyi termal sonuçlara 0.02 konsantrasyonlu nanoakışkanda ulaşılmıştır.

\section{Isı transferi}

$\% 0.01, \% 0.02$ ve \%0.03 hacimsel nanopartikül konsantrasyonlarına sahip saf su ve su bazlı grafen nanoakışkan için hacimsel debilerine bağlı 1S1 transfer miktarları Şekil 2'de gösterilmektedir. Nanoakışkan kullanılan deneylerde elde edilen 1s1 transfer oranları saf suya oranla daha yüksektir. Şekil 2'de, saf su ve su bazlı grafen nanoakışkanın hacimsel debisini artırarak 1sı transfer oranının arttığı açıkça görülmektedir.

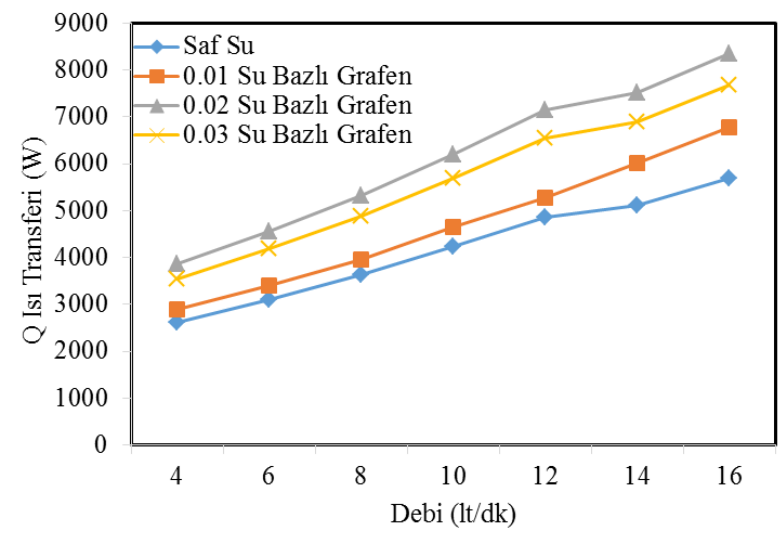

Şekil 1. Deney akışkanları için usı transferi ve hacimsel debi

Saf su ile yapılan deneyde, 1 sı transferi 4 lt/dk'lik debide $2628 \mathrm{~W}$ ve 16 lt/dk'lik debide 5863 W'dir. Hacimsel konsantrasyonları \%0.01, $\% 0.02$ ve $\% 0.03$ sahip nanoakışkanlar 
kullanıldığında farklı hacimsel debilerde 1s transfer miktarında artışlar olmaktadır. \%0.01 hacimsel konsantrasyona sahip nanoakışkan deneyinde 1s1 transfer oranları $4 \mathrm{lt} / \mathrm{dk}$ debide $\% 10.09$ ile 16 lt/dk debide \%19.21 artmıştır. Şekil 2'de, nanoparçacıkların hacimsel konsantrasyonu arttıkça isı transfer hızının arttığ1 görülmektedir. Ancak 1sı transferindeki bu artış nanopartiküllerin hacimsel konsantrasyonu $\% 0.02$ oluncaya kadar devam etmektedir. Konsantrasyon miktarı arttıkça 1sı transferinde artış olmamaktadır. Isı transferinin en yüksek olduğu akışkan \%0.02 hacimsel konsantrasyonlu nanoakışkandır. Nanopartiküllerin hacimsel konsantrasyon seviyesi belirli değerlerin üzerine çıktığında viskozitedeki artışa bağlı olarak radyatör borularında sınır tabaka kalınlığını artırmakta olup ve 1s1 transfer miktarı artmamaktadır [26,30].

\section{Toplam isı transfer katsayısı}

$\mathrm{Su}$ ve $\% 0.01, \% 0.02$ ve $\% 0.03$ nanopartikül hacimlerine sahip su bazlı grafen nanoakışkan için hacimsel debilerine bağlı toplam isı transfer katsayıları Şekil 3'de gösterilmektedir. Nanoakışkanların hacimsel debisi artıkça 1sı transferi katsayısı artmaktadır.

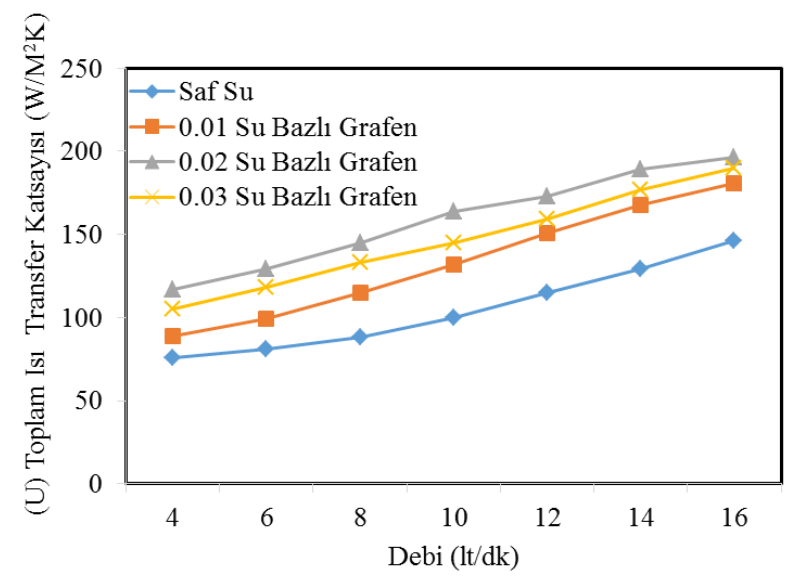

Şekil 2. Deney akışkanları için debiye bağlı toplam isı transfer katsayısı

Nanoparçacıkların hacimsel konsantrasyonu $\% 0.02$ 'den $\% 0.03$ 'e yükseltildiğinde, toplam 1s1 transfer katsayılarının düștüğü görülmektedir. Saf su kullanıldığında, toplam isı transfer katsayıs 4 lt/dk'llk debide $76 \mathrm{~W} / \mathrm{m}^{2} \mathrm{~K}$ ve 16 $\mathrm{lt} / \mathrm{dk}$ 'da ise $146 \mathrm{~W} / \mathrm{m}^{2} \mathrm{~K}$ olmuştur. \%0.01 hacimsel konsantrasyona sahip nanoakışkanın toplam 1s1 transfer katsayıs1, saf suya kiyasla 4lt/dk'llk debide \%17.06 ve 16 lt/dk'lık debide $\% 23.90$ artmıştır. 4 lt/dk'lık hacimsel debide
\%0.02 hacimsel konsantrasyonlara sahip nanoakışkan kullanımında toplam 1sı transfer katsayısında \%53.79 artış görülmektedir. 16 lt/dk'llk hacimsel debide \%0.03 hacimsel konsantrasyonlara sahip nanoakışkan kullanımında ise toplam 1si transfer katsayısında $\% 38.41$ artış olmuştur. \%0.02 hacimsel konsantrasyonlara sahip su bazlı grafen nanoakışkanın, 16 lt/dk debide toplam 1s1 transfer katsayısında artış \%38.43 olmuştur. 16 lt/dk debide \%0.03 hacimsel konsantrasyonlara sahip nanoakışkan kullanımında toplam 1s1 transfer katsayısındaki artış \%29.88 olmuştur.

\section{Nusselt sayısı}

Nusselt say1s1 ile Reynolds say1s1 arasındaki değişim, \%0.01, \%0.02 ve \%0.03 hacimsel nanopartikül konsantrasyonlarına sahip su ve su bazlı grafen nanoakışkan için Şekil 4'de gösterilmektedir. Reynolds sayısına bağlı olarak Nusselt sayısı artmıştır. Bununla birlikte, nanoakışkanın Nusselt sayı değerleri suya göre daha yüksektir. Reynolds sayısı radyatör boru geometrisine, akış hızına, akışkanının yoğunluğuna ve viskozitesine bağlıdır. \% 0.02 hacimsel konsantrasyona sahip nanoakışkan kullanılan deneyde Nusselt sayısını en büyük değerlere ulaşmaktadır.

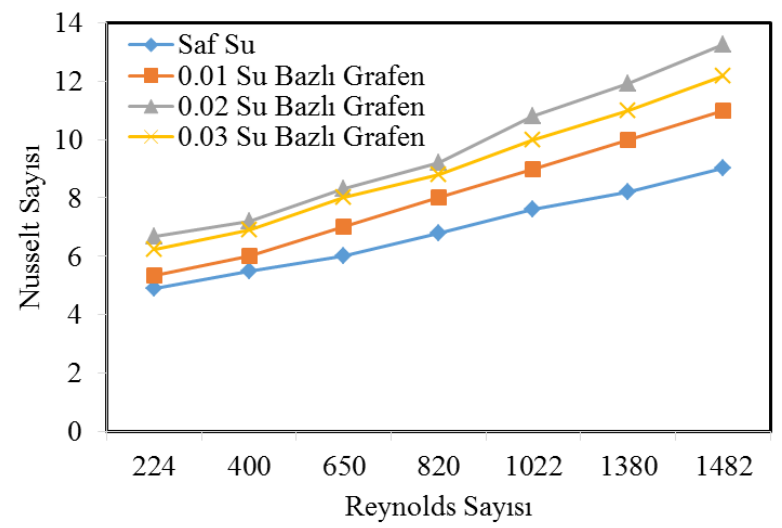

Şekil 3. Deney sıvıları için Nusselt sayısı ile Reynolds saylst

Deneyde saf su akışkan olarak kullanıldığında, Reynolds sayıs1 224 iken Nusselt sayıs1 4.92 değerini almaktadır. Reynolds sayısı 1482 olduğunda ise Nusselt sayısı 9.02 olmaktadır. $\% 0.01$ hacimsel konsantrasyona sahip su bazlı nanoakışkanın kullanıldığ 1 deneyde Nusselt say1s1 4lt/dk debide \%8.62, $16 \mathrm{lt} / \mathrm{dk}$ debide ise $\% 14.69$ artmaktadır. \%0.02 hacimsel konsantrasyonlara sahip su bazlı grafen 
nanoakıșkan kullanıldığında, Reynolds sayısı 224 iken Nusselt sayısında \%36.03 artış olmuştur. \%0.03 hacimsel konsantrasyonlara sahip su bazlı grafen nanoakışkan kullanıldığında ise Reynolds sayısı 224 iken Nusselt sayıs1 \%26.42 olmuştur.

\section{Basınç düşüş değerleri}

Reynolds sayısı değerlerine göre basınç düşüşündeki değerler șekil 5'de verilmiş olup, su ve su bazlı grafen nanoakışkan için Reynolds sayısı arttıkça basınç düşüşünün $\operatorname{arttığı~}$ görülmektedir. Nanoakışkan kullanılan deneylerde basınç düşüş değerleri suya göre oldukça yüksektir. Su kullanılan deneylerde basınç düşme değerleri Reynolds sayısı 224 iken 196.26 Pa ve Reynold sayıs1 1482 iken 2474.26 Pa'dır. \%0.01 hacimsel su bazlı nanoakıșkan kullanılan deneyde basınç düşüş değerleri 4 lt/dk debide \%19.89 artmış ve 16 lt/dk'lık debide ise \%57.69 artmıştır. \%0.02 hacimsel konsantrasyonlara sahip su bazlı grafen nanoakışkanda Reynolds sayısı 224 iken basınç düșüșü \%78.52 artmıștır. \%0.03 hacimsel konsantrasyonlara sahip su bazlı grafen nanoakışkanda, Reynolds sayısı 224 iken basınç düşüşü \%106.85 artış göstermiştir.

$\% 0.01, \quad \% 0.02, \quad \% 0.03 \quad$ hacimsel konsantrasyonlara sahip su bazlı grafen nanoakışkanın basınç düşüşündeki ortalama artışları $\% 36.27, \% 54.70$ ve $\% 73.00$ değerlerine ulaşmaktadır. Basınç düşmesindeki artışlar su bazlı grafen nanoakıșkanın fiziksel özelliklerinden kaynaklanmaktadır $\quad[9,18]$. Nanoakışkanların yoğunlukları ve viskoziteleri yüksek olduğundan basınç düşüşündeki değerler saf suya göre daha yüksektir [31].

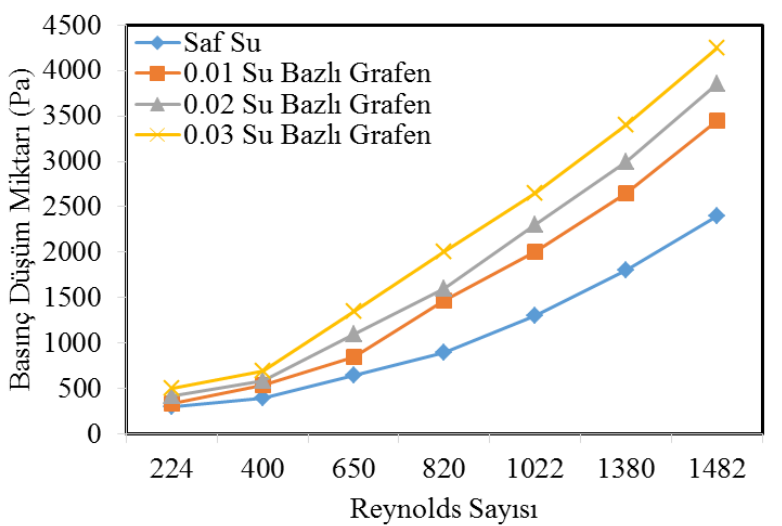

Şekil 4. Deney sıvıları için Reynolds sayısı ile basınç düşüşü

\section{Radyatör Çıkış Sıcaklığı}

Soğutma sistemlerinde amaç, motorda 1sınmış akışkanın sıcaklığını radyatörde belirli sicaklıklara kadar soğutarak içten yanmalı motorun ideal şartlarda çalışmasını sağlamaktır. $\mathrm{Bu}$ nedenle radyatör giriş ve çıkış sıcaklık değerleri oldukça önemlidir. Radyatör çıkış sıcaklıkları ile hacimsel debi ilişkisi, Şekil 6'da görülmektedir. Su bazlı grafen nanoakışkanın kullanıldığı deneylerde radyatörün çıkış sıcaklığının azaldığı görülmektedir. Radyatörün 1sıl verimliliği, nanoakışkanlar kullanıldığında yükselmiştir. Ancak debideki artış 1S1 transfer hızını düşürmekte ve radyatörün çıkış sıcağını artırmaktadır [32].

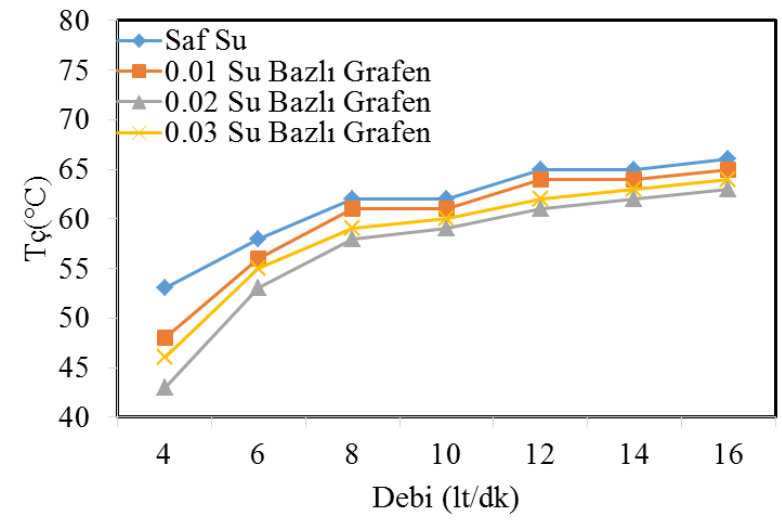

Şekil 5. Debiye bağlı olarak deney sıvıları için radyatör çıkıs sıcaklığı

\section{Sonuçlar}

$\mathrm{Bu}$ çalışmada önemli sonuçlar elde edilmiştir. Araç soğutma sistemlerinde su bazlı grafen nanoakıșkanın kullanılması sonucunda 1S1 transfer oran1, toplam 1s1 transfer katsay1s1 ve Nusselt say1s1 gibi 1s1l performans parametrelerinde önemli neticeler alınmıştır. $\% 0.02$ hacimsel nanoparçacık konsantrasyonuna sahip nanoakışkan kullanılarak yapılan deneyde 1S1 transfer hızındaki maksimum artış, \%47 olarak elde edilmiştir. Toplam isı transfer katsayısı ve Nusselt sayısındaki maksimum artış, $\% 0.02$ hacimsel nanoparçacık konsantrasyonuna sahip nanoakışkan kullanılarak sırasıyla \%52 ve $\% 34$ olarak elde edilmiștir. \%0.02 hacimsel nanopartikül konsantrasyonuna sahip nanoakışkan kullanılan deneyde basınç düşüşündeki artış \%49 olmuştur. Isıl performans parametrelerindeki en yüksek değerler nanoparçacıkların hacimsel konsantrasyon seviyesi \%0.02 iken sağlanmıştır. 
Hacimsel konsantrasyonu \%0.02'den \%0.03'e yükseltildiğinde 1S1 transfer oran1, toplam 1S1 transfer katsayısı ve Nusselt sayısında düşüşler görülmektedir. Ayrıca basınç düșüş miktarı da azalmaktadır. Su yerine su bazlı grafen nanoakışkanın kullanıldığında otomobil radyatörünün 1sıl verimliliği oldukça yükselmiştir. Özellikle \%0.02 hacimsel nanoparçacık konsantrasyonuna sahip nanoakışkan kullanıldığında en yüksek 1sıl verimlilik sağlanmıștır.

Sonuç olarak araç soğutma sisteminde su bazlı grafen nanoakışkan kullanılması 1sıl performanslar açısından oldukça iyi sonuçlar doğurmuştur. Dolayısıyla su bazlı grafen nanoakışkanın otomobil soğutma sistemlerinde kullanılması ısıl verimliliği artırmaktadır.

\section{Kaynaklar}

[1] Maxwell, J.C. (1904). A Treatise on Electricity and Magnetism, Oxford University Press, Cambridge.

[2] Ali, H.M., Azhar, M.D., Saleem, M., Saeed, Q.S., Saieed, A., (2015), Heat transfer enhancement of car radiator using aqua based magnesium oxide nanofluids, Thermal Science 19(6), 2039-2048.

[3] Ali, H.M., Ali, H., Liaquat, H., Maqsood, H.T.B., Nadir, M.A., (2015), Experimental investigation of convective heat transfer augmentation for car radiator using $\mathrm{ZnO}-$ water nanofluids, Energy, 84, 317-324.

[4] Karabulut, K., Buyruk, E., Kilinc, F., (2020). Experimental and numerical investigation of convection heat transfer in a circular copper tube using graphene oxide nanofluid, J Braz. Soc. Mech. Sci. Eng. 42 (230), 1-16.

[5] Bhogare, A.R.A., Kothawale, B., Bodkhe, P.P., Gawali, A., (2014). Performance investigation of Automobile Radiator operated with Nanofluids Based Coolant, International Journal of Thermal Technologies, 4(2), 2277-4114.

[6] Qasim, M., Sajid, Kamran, M., Ammar, M. Jamal, A.M., Javaid M.Y., (2020). Heat Transfer Enhancement of an Automobile Engine Radiator using $\mathrm{ZnO}$ Water Base Nanofluids, J. Therm. Sci. 11630 (20), 1263-9.

[7] Ali, M., El-Leathy, A., Al-Sofyany Z., (2014). The effect of nanofluid concentration on the cooling system of vehicles radiator, Advances in Mechanical Engineering, 6, 962510.

[8] Heris, S.Z., Pour, M.B., Mahian, O., Wongwises, S., (2014). A comparative experimental study on the natural convection heat transfer of different metal oxide nanopowders suspended in turbine oil inside an inclined cavity, International Journal of Heat and Mass Transfer, 73, 231-238.

[9] Leong, K., Saidur, R., Kazi, S., Mamun, A., (2010). Performance investigation of an automotive car radiator operated with nanofluid-based coolants (nanofluid as a coolant in a radiator), Applied Thermal Engineering, 30, 2685-2692.

[10] Peyghambarzadeh, S., Hashemabadi, S., Jamnani, M.S., Hoseini, S., (2011). Improving the cooling performance of automobile radiator with $\mathrm{Al}_{2} \mathrm{O}_{3} /$ water nanofluid, Applied Thermal Engineering, 31(10), 1833-1838.

[11] Peyghambarzadeh, S., Hashemabadi, S., Naraki, M., Vermahmoudi, Y., (2013). Experimental study of overall heat transfer coefficient in the application of dilute nanofluids in the car radiator, Applied Thermal Engineering, 52(1) ,8-16.

[12] Naraki, M., Peyghambarzadeh, S., Hashemabadi, S., Vermahmoudi, Y., (2014). Parametric study of overall heat transfer coefficient of $\mathrm{CuO} /$ water nanofluids in a car radiator, International Journal of Thermal Sciences, 66, 82-90.

[13] Hussein, A.M., Bakar, R., Kadirgama, K., (2014). Study of forced convection nanofluid heat transfer in the automotive cooling system, Case Studies in Thermal Engineering, 2, 50-61.

[14] Nieh, H.M., Teng, T.P., Yu, C.C., (2014). Enhanced heat dissipation of a radiator using oxide nanocoolant, International Journal of Thermal Sciences, $77,252-261$.

[15] Baby, T.T., Ramapraphu, S., (2014). Enhanced Convective Heat Transfer Using Grap-hene Dispersed Nanofluids, Nanoscale Res. Lett., 6- 289.

[16] Chavan, D., Pise, A.T., (2014). Performance investigation of an automotive car radiator operated with nanofluid as a coolant, Journal of Thermal Science and Engineering Applications, 6(2), 021010.

[17] Heris, S.Z., Shokrgozar, M., Poorpharhang, S., Shanbedi, M., Noie, S., (2014). Experimental study of heat transfer of a car radiator with $\mathrm{CuO} /$ ethylene glycol-water as a coolant, Journal of Dispersion Science and Technology, 35(5), 677-684.

[18] Akhavan-Zanjani, H., Saffar-Avval, M., Mansourkiaei, M., Sharif, F., Ahadi, M., (2016). Experimental Investigation of Laminar Forced Convective Heat Transfer of Graphene-Water Nanofluid Inside a Circular Tube, Int. J. Thermal Sci.,100, 316-323. 
[19] Kilinc, F., Buyruk, E., Karabulut, K., (2019). Grafen Tabanlı Nanoakışkanların Araç Radyatörü Soğutma Performansı Üzerindeki Etkisinin Deneysel Analizi, Iğdır Üniversitesi Fen Bilimleri Enstitüsü Dergisi, 9(2), 1046-1056.

[20] Kılınç, F., Buyruk, E., Karabulut, K., (2020). Experimental investigation of cooling performance with graphene based nano-fluids in a vehicle radiator, Heat Mass Transfer 56, 521-530.

[21] Kılınç, F., Buyruk, E., Karabulut K., (2017). An Experimental Study for Heat Transfer Enhancement of Graphene Nanoribbon Nanofluid in an Automobile Radiator, 8th International Advanced Technologies Symposium, 1439-1446.

[22] Kılınç, F., Buyruk, E., Karabulut K., (2019). Araç Radyatörünün Is1 Transferi Performansinın Su Tabanlı Nanoakışkanlar Kullanılarak Deneysel Olarak Araştırılması, Tesisat Mühendisliği, 170, 37 46.

[23] Singh, V., Joung D., Zhai L., Das S., Khondaker S., Seal S., (2014). Graphene Based Materials: Past, Present and Future, Progress in Materials Science, $56,1178-1271$.

[24] Novoselov, K., Geim, A. K., Morozov, S., Jiang, D., Grigorieva, M. K. I., Dubonos, S., Firsov, A., (2005). Two-Dimensional Gas of Massless Dirac Fermions in Graphene, Nature, 438 (7065),197-200.

[25] Yu, W., Xie, H., Chen, L., Li, Y.. (2010). Enhancement of Thermal Conductivity of KeroseneBased Fe3O4 Nanofluids Prepared via PhaseTransfer Method, Colloids and Surfaces A, 355, (13), 109-113.
[26] Li, Y., Fernández-Seara, J., Du, K., Pardiñas, Á.Á., Latas, L.L., Jiang, W., (2016). Experimental investigation on heat transfer and pressure drop of $\mathrm{ZnO}$ /ethylene glycol-water nanofluids in transition flow, Applied Thermal Engineering, 93, 537-548.

[27] Pak, B.C., Cho, Y.I., (1998). Hydrodynamic and heat transfer study of dispersed fluids with submicron metallic oxide particles, Experimental Heat Transfer an International Journal, 11(2), 151170.

[28] Holman, J.P., Gajda, W.J., (2001). Experimental methods for engineers, McGraw-Hill, New York.

[29] Shah, R.K., London, A.L., (1978). Laminar flow forced convection in ducts: a source book for compact heat exchanger analytical data, Advances in heat transfer, Supplement. New York: Academic Press, 109.

[30] Zeinali, H.S., Razbani, M.A., Estellé, P., Mahian, O., (2015). Rheological behavior of zinc-oxide nanolubricants, Journal of Dispersion Science and Technology, 36(8), 1073-1079.

[31] Taghizadeh, T.Z., Heris S.Z., Moradi M., Kahani M., (2016). The study on application of $\mathrm{TiO} 2 /$ water nanofluid in plate heat exchanger of milk pasteurization industries, Renewable and Sustainable Energy Reviews, 2016, 58,1318- 1326.

[32] Bhimani, V., Rathod, P., Sorathiya, A., (2013). Experimental study of heat transfer enhancement using water based nanofluids as a new coolant for car radiators, International Journal of Emerging Technology and Advanced Engineering, 2013, 3(6), 295-302.

[33] Maxwell J.C., (1873). A treatise on electricity and magnetism, vol 1. Clarendon Press, Oxford, 1873. 